\title{
La imprescriptibilidad de las acciones civiles por daños y perjuicios emanadas de delitos de lesa humanidad
}

(Una mirada crítica sobre el fallo "Villamil" de la C.S.J.N.)

Por Díaz Martinez

"Queda claro, entonces, que se trata ésta, de una institución más cercana a la seguridad jurídica que a la justicia."

Botassi Carlos en Lesa humanidad, responsabilidad civil del Estado y prescripción

\section{I.- Introducción}

El presente artículo tiene por objeto principal realizar un análisis de la aplicación que tiene la institución de la prescripción liberatoria, respecto a las acciones civiles resarcitorias por daños y perjuicios derivadas de los delitos de lesa humanidad perpetrados en nuestro país.

El abordaje de esta temática obedece a que la jurisprudencia nacional se ha mostrado contradictoria en torno a aceptar que la imprescriptibilidad de los crímenes contra la humanidad se hace extensiva a la acción civil que emanan de estos ilícitos internacionales.

Recurriendo a diversas fuentes, como la doctrina, la jurisprudencia, disposiciones legales y convenciones e instrumentos internacionales sobre Derechos Humanos, entre otras, planteo la improcedencia de la prescripción civil, inaplicable ante situaciones de violaciones manifiestas a los Derechos Humanos, para eludir la responsabilidad del Estado y los represores condenados.

\section{II.- Posiciones}

1.- Posición negatoria: la posición negativa respecto a la imprescriptibilidad de la acción civil por daños emanados de los delitos de lesa humanidad se expresa tanto en jurisprudencia como en la doctrina, a saber:

a.- Jurisprudencia: A fin de ilustrar la posición negatoria en la jurisprudencia nacional, podemos referirnos a los siguientes fallos más relevantes: Los tribunales hace un tiempo ya habían establecido "dos posturas contrapuestas: 10) el criterio de la prescriptibilidad de la acción civil; y 20) la contraria, que postula que la acción resulta imprescriptible”(Montilla, 2016: 2).

La primera posición "fue sostenida por la Corte Suprema en la causa “Larrabeiti Yánez”, del 30-10-07. El Máximo Tribunal estimó que la acción civil que reclamaba resarcimiento podía prescribir, pues "es inadmisible el argumento según el cual la acción para reclamar el resarcimiento patrimonial derivado de la 
desaparición forzada de personas es imprescriptible porque nace de delitos de lesa humanidad, pues la primera atañe a materia disponible y renunciable, mientras que, desde la óptica del reproche penal, la persecución se funda en la necesidad de que los crímenes de esa naturaleza no queden impunes, es decir, en razones que exceden el interés patrimonial de los particulares afectados"(Montilla, 2016: consid. $5^{\circ}$ ).

Es decir, estos jueces sostenían que, "al tratarse de una cuestión puramente patrimonial, tal reclamo reviste los caracteres de disponibilidad y renunciabilidad, lo que tornaría aplicable las normas de prescripción de derecho común (Olivares, CSJN, 1988).

Luego, el día 28 de marzo de 2017, la C.S.J.N. en un fallo reciente y muy polémico reafirmo la doctrina del caso "Larrabeiti Yánez".

Se trata de la causa "Villamil, Amelia Ana c/ Estado Nacional s/ daños y perjuicios (CSJ 203/2012 (48-V)/CS1)", en donde se "dictó una sentencia en la que el voto de la mayoría fue firmado por los jueces Ricardo Lorenzetti, Elena Highton de Nolasco y Carlos Rosenkrantz, mientras que los jueces Juan Carlos Maqueda y Horacio Rosatti opinaron en disidencia. Mediante el voto conjunto de los jueces Lorenzetti, Highton de Nolasco y Rosenkrantz, la Corte Suprema concluyó que dichas reclamaciones no son imprescriptibles y que, por ende, para dar lugar a una sentencia condenatoria por la responsabilidad del Estado, las acciones están sometidas a las disposiciones que establecen el plazo de prescripción dentro del cual deben ser útilmente promovidas. Los jueces Maqueda y Rosatti votaron en disidencia sosteniendo que esta clase de acciones eran imprescriptibles, fundando sus opiniones en mediante sendos votos individuales" (Centro de Información Judicial, 2017).

Ahora bien, en "el caso ya existía un precedente "Larrabeiti Yáñez", dictado en 2007 y suscripto por los jueces Lorenzetti, Highton de Nolasco, Fayt, Petracchi y Argibay (Fallos: 330:4592), el que resulta de aplicación directa al caso y al que se remite. Allí se diferenciaron ambas situaciones, sobre la base de que la acción para reclamar el resarcimiento patrimonial es materia disponible y renunciable, mientras que la imprescriptibilidad de la persecución penal en materia de lesa humanidad se funda en la necesidad de que los crímenes de esa naturaleza no queden impunes, es decir, en razones que exceden el interés patrimonial de los particulares afectados En suma, se sostuvo que en un caso está en juego el interés patrimonial exclusivo de los reclamantes, mientras que en el otro está comprometido el interés de la comunidad internacional, de la que Argentina es parte, en que tales delitos no queden impunes, lo que impide cualquier asimilación de ambos tipos de casos y, por lo tanto, que se declare la imprescriptibilidad de las acciones de daños como la aquí intentada. La opinión de la mayoría dejó en claro que no existía al momento en que la prescripción de la acción operó -16 de noviembre de 1995- ninguna norma que dispusiera esa solución. Agregó que tampoco resultaría aplicable al caso la imprescriptibilidad fijada en el artículo 256 in fine del Código Civil y Comercial, en virtud de lo dispuesto expresamente por el artículo 2537 del mismo cuerpo legal (Centro de Información Judicial, 2017). 
b.- Doctrina: Si bien "Entre la doctrina predomina la posición de considerar que la acción de resarcimiento civil por los delitos de lesa humanidad resulta imprescriptible..."(Montilla, 2016: 2), no por ello vamos a dejar de analizar la posición negativa sobre la cuestión.

Entre los doctrinarios de la tesis negatoria encontramos la visión de Aída Kemelmajer de Carlucci que nos dice

(...) un nuevo paso, muy peligroso en mi opinión, se ha dado a favor de la imprescriptibilidad en un caso en el que se demando a un particular, a quien se sindico como cómplice de los delitos de lesa humanidad ... Por mi parte, no me animo a vaticinar la imprescriptibilidad, especialmente, frente a lo dispuesto por las Reglas de UN, antes transcriptas, que expresamente aceptan la prescriptibilidad, si bien señalando que el plazo no debe ser angustiante (Kemelmajer, 2013).

Por otra parte, Ricardo Guibourg refiriéndose a una posible respuesta de la $\mathrm{CIDH}$ sobre el tema, nos dice "Se ha pronunciado sobre la imprescriptibilidad de la acción penal, pero no sobre la civil. Es difícil decir qué es lo que resolvería, pero el impulso justiciero que se advierte en el derecho internacional humanitario permite conjeturar una aceptación de la imprescriptibilidad" (Montilla, 2016: 2). Guibourg alerta, entonces, sobre el problema de la eliminación de las garantías, a la manera del derecho penal del enemigo, que puede extenderse a un "derecho civil del enemigo.

Dice Guiborug (2012) que "no se pretende defender a tales enemigos, que también son los nuestros, pero como cada uno tiene sus propios grupos de enemigos, tratemos de reconstruir un derecho general en el que las preferencias morales del intérprete, buenas o malas, desempeñen un papel menos trascendente que el que se le asigna crecientemente".

Edgardo López Herrera (2016) al respecto dice que "no es posible aplicar esa especie de paralelismo de las formas, ni es cierto que la imprescriptibilidad penal provoque una imprescriptibilidad civil. Incluso los autores que propugnan la imprescriptibilidad de la acción civil reconocen que "los instrumentos internacionales de derechos humanos reconocen universalmente [...] la imprescriptibilidad de los crímenes de lesa humanidad, incluyendo la desaparición forzada de personas y el derecho de las víctimas, de la cual no necesariamente se sigue que las consecuencias civiles de tales crímenes de Derecho Internacional no podrían estar sujetas a prescripción”.

Además, López Herrera (2016) nos dice que "La prescripción penal y la civil, si bien ambas son extintivas, una de la pena y de la acción penal y la otra de la acción civil, son distintas, porque las acciones que extinguen también lo son”.

Y continúa:

La diferencia más sustancial es que la prescripción penal de delitos de lesa humanidad, por el principio de personalidad de la pena, declara imprescriptibles acciones o penas inseparables de la persona. 
Dicho de otra manera, en la prescripción penal, aun de las acciones imprescriptibles, hay un claro límite final de la acción penal que es la muerte del imputado. En cambio, en las acciones civiles rigen dos principios distintos: el de la transmisibilidad del crédito y de la deuda y el de la posibilidad de accionar contra otros responsables. Si fuese cierta esta relación entre la imprescriptibilidad penal y civil, deberíamos aceptar que cundo el imputado muere la acción civil comienza a prescribir, lo que no es cierto si la persona sigue desaparecida, como tampoco lo es que si se encuentran los cadáveres de las víctimas, la acción penal del delito de lesa humanidad de desaparición forzada de personas inicia su prescripción (Herrera, 2016).

Declarar imprescriptible una acción de daños, nos dice López Herrera (2016)

quiere decir que es posible reclamar los daños no sólo al autor de la desaparición sino también a sus herederos y a los responsables y obligados a garantizar su conducta, en especial al Estado, que ya ha ofrecido una reparación a las víctimas en cumplimiento de los tratados internacionales de derechos humanos, reparación que está sujeta a plazos de caducidad.

Asimismo, López Herrera dice que sobre este punto se ha pronunciando por primera vez la Corte Suprema en el caso anotado, y ha dicho que este tipo de acciones civiles de daños no son imprescriptibles. Así, en el consid. 5 del voto de la mayoría, conformada por los jueces Lorenzetti, Highton de Nolasco, Petracchi y Argibay, claramente se dice que

(...) no es atendible el argumento en virtud del cual la acción para reclamar el resarcimiento patrimonial es imprescriptible porque nace de delitos de lesa humanidad, imprescriptibles desde la óptica del reproche penal. Ello es así porque la primera atañe a materia disponible y renunciable, mientras que la segunda, relativa a la persecución de los delitos de lesa humanidad, se funda en la necesidad de que los crímenes de esa naturaleza no queden impunes, es decir, en razones que exceden el interés patrimonial de los particulares afectados (conf. Fallos 311:1490).

López Herrera (2016) dice que "En nuestra opinión, el fallo tiene notables aciertos, y sólo hemos disentido en el inicio del curso de la prescripción... "Con este fallo quizás haya un ahorro en las indemnizaciones a pagar."

En este caso la C.S.J.N:

sabe que los hermanos Larrabeiti Yañez pueden cobrar la indemnización prevista en la ley 24.411. No sólo ellos pueden hacerlo sino también cualquier otra víctima, aun si no inició acción 
de daños hasta la fecha por la prórroga contenida en la ley 26178. Dicho de otro modo: la Corte está muy al tanto de que no deja a nadie sin una reparación a cargo del Estado. No interesa que no sea integral, pero es una indemnización de daños al fin, que en la medida en que no sea confiscatoria con la relación a los daños sufridos será constitucional

\section{Finalmente alega López Herrera (2016) que}

Con este nuevo criterio difícilmente pueda demandarse al Estado por la acción común de daños. Además, muchas de las acciones iniciadas dos años después de conocido el informe de la Conadep se verán destruidas por la prescripción. Las víctimas sólo tienen el camino de la reparación administrativa y tarifada, mientras no se decida no renovar los plazos de caducidad. Es eso o la nada. Como dice la canción, el Estado ahora tiene la sartén por el mango y el mango también. Con "Larrabeiti Yañez" son las mayorías políticas del Congreso las que decidirán hasta cuándo se puede solicitar este tipo de beneficios

2.- Posición afirmativa: la posición afirmativa de la imprescriptibilidad de la acción civil por daños emanados de los delitos de lesa humanidad, también se ve reflejada tanto en la jurisprudencia como en la doctrina:

a.- Jurisprudencia: Los fundamentos a favor de la imprescriptibilidad de la acción civil por daños fueron sostenidos por varios tribunales inferiores.

La Cámara Nacional del Trabajo, en su sala V, mediante sentencia del 2 de febrero de 2012 dictada "en los autos "Ingeniero contra Techint", falló considerando que la acción dirigida contra una persona jurídica resultaba imprescriptible. El Tribunal, con argumentos liminares de los doctores Arias Gibert y Zas, entre otras razones, estimó que al ser el delito de lesa humanidad imprescriptible y, por lo tanto, que los autores, consejeros o cómplices pueden ser perseguidos penalmente por una acción imprescriptible, ninguna razón existe para que el resarcimiento del daño causado resulte prescriptible, máxime si esta correlación entre prescriptibilidad de la acción penal y de la acción civil es contemplada incluso por la norma del art. 3982 bis del cód. civil en su redacción de la ley nacional 17.711" (Montilla, 2016: 2).

Comentando el fallo, Montilla Zavalía nos dice que "Asimismo, la mayoría de los jueces argumentó que si los crímenes no son susceptibles de prescripción, al no distinguirse en la convención entre la acción resarcitoria o punitiva, el principio de imprescriptibilidad debe aplicarse a ambos tipos de acciones, pues, de lo contrario, se condenaría a las personas de existencia visible y se permitiría que las personas de existencia ideal (insusceptibles de condena penal) gocen de los bienes que el crimen ha provocado (del voto del Dr. Enrique Néstor Arias Gibert - mayoría)." (Montilla, 2016: 2). 
Los jueces referidos también

juzgaron que el instituto de la prescripción liberatoria es una disposición de derecho interno de gradación inferior a la constitucional, y que cede irremediablemente frente a una norma de carácter internacional receptada en la Constitución Nacional, de manera tal que, con respecto a las indemnizaciones derivadas de los delitos de lesa humanidad, no es aplicable plazo alguno de prescripción, ya que las fuentes del derecho internacional imperativo consideran como aberrantes la ejecución de cierta clase de actos y sostienen que, por ello, esas actividades deben considerarse incluidas dentro del marco normativo que procura la persecución de aquellos que cometieron esos delitos; según el corpus iuris del derecho internacional, los crímenes de lesa humanidad constituyen en sí mismos graves violaciones a los derechos humanos y afectan a la humanidad toda, son serios actos de violencia que dañan a los seres humanos al golpear lo más esencial para ellos: su vida, su libertad, su bienestar físico, su salud y su dignidad (Montilla, 2016: 2).

\section{Por último,}

se juzgó que la imprescriptibilidad de los delitos de lesa humanidad es un principio derivado tanto del derecho internacional consuetudinario cuanto del convencional; la interpretación del alcance del mencionado principio no debe limitarse a las normas consagradas en este último, por lo tanto, el hecho de que los textos de las normas internacionales interpretadas desde una perspectiva estrictamente literal conlleven la limitación del alcance del principio a la acción penal no obsta a una hermenéutica extensiva (Montilla, 2016: 2).

La sala II de la Cámara Federal de Apelaciones de La Plata en el caso "Villamil" (JA 2007-III-647), en análoga visión "se expidió que juzgó que la acción resarcitoria de los daños derivados de delitos de lesa humanidad no pueden separarse de la pretensión jurídicamente demandable; debido a ello "no resulta aplicable plazo de prescripción alguno”. Para así decidir, la Cámara (voto del Dr. Fleicher al que adhirió el Dr. Schiffrin) citó en apoyo de la imprescriptibilidad de la acción civil lo resuelto por la Corte IDH en la causa "Almonacid Arellano y otros c. Chile”, del 26-9-06, en la cual se resolvió que la obligación estatal de reparar los daños posee carácter accesorio respecto del delito de lesa humanidad que los ha generado y no puede ser modificada o incumplida invocando disposiciones de derecho interno" (Montilla Zavalia, 2015)

Entonces, en esa oportunidad se afirmo, que "ninguna duda cabe acerca de que el instituto de la prescripción liberatoria es una disposición de derecho interno, de gradación inferior a la constitucional. Y por ser de derecho interno, cede irremediablemente frente a una norma de carácter internacional receptada en la 
Constitución Nacional. De manera tal que, con respecto a las indemnizaciones derivadas de delitos de lesa humanidad, no es aplicable plazo alguno de prescripción, ya sea si la acción se iniciare a partir de lo que establece el art. 29 del cód. penal, o si se intentare en sede civil "(Montilla Zavalia, 2015).

Además, vale tener presente, que los precedentes jurisprudenciales anteriormente citados fueron seguidos y sostenidos por varios tribunales federales de Argentina, tales como en las causas conocidas coloquialmente como "Oesterheld"1, "Bozzi", "Ragone" y "Toledo de Ygel"4, entre otras más.

El día 3 de marzo de 2017 el Procurador Fiscal Dr. Víctor Abramovich dictamino que "La eficacia temporal de la imprescriptibilidad de las acciones derivadas de delitos de lesa humanidad prevista en el mencionado artículo 2.561 del Código Civil y Comercial de la Nación es determinada por el principio general establecido en el artículo 7 de ese código. En este sentido, entiendo que no es aplicable el artículo 2.537, que establece que "Los plazos de prescripción en curso al momento de entrada en vigencia de una nueva ley se rigen por la ley anterior [...]". En efecto, tal como expuse, el artículo 2.561 no modifica los plazos de prescripción, sino que directamente excluye de la regla de la prescripción a las consecuencias civiles de los ilícitos más aberrantes para la conciencia universal en consonancia con los principios internacionales. Por ello, ese supuesto no se encuentra comprendido por el artículo 2.537 que rige la aplicación en el tiempo de las modificaciones de los plazos de prescripción. De acuerdo con el artículo 7 y con la doctrina de la Corte Suprema, la ley aplicable a las relaciones y situaciones jurídicas que se constituyan en el futuro, a las relaciones y situaciones jurídicas existentes en cuanto no estén agotadas, y a las consecuencias que se encuentren en curso o no se hayan consumido bajo el régimen anterior (Fallos: 327:1139, "Cordero"; 338:706, "D.L.L., V.G.”; 339:349, “Terren”.). 5

En la causa "Villamil", los jueces Maqueda y Rosatti votaron en disidencia enrolándose de esa manera en la posición que acepta la imprescriptibilidad de las acciones civiles por daños y perjuicios derivadas de los delitos de lesa humanidad.

1 “Oesterheld, Diana Irene s/ su secuestro y desaparición. Inicidente de apelación”, Expte. 50.656/08, sentencia del 19-06-2008.

2 Juzgado Federal No 2 de Mar del Plata, Expte. 77331/8: "Bozzi, Carlos c/Estado Nacional s/ Daños y Perjuicios Ordinario", de fecha 2010.

3 Tribunal Oral en lo Criminal Federal de Salta, Expte. № 3115/09: "c/HERRERA, Rubén Nelson; HERRERA, Pedro Javier; GENTIL, Miguel Raúl; MULHALl, Carlos Alberto; ZANETTO, Jorge Héctor; GUIL, Joaquín y SORAIRE, Andrés del Valle s/Encubrimiento en concurso ideal con el tipo penal de omisión de represión de delincuentes; homicidio calificado en dos hechos en concurso real y lesiones; coacción agravada y lesiones, en perjuicio de Miguel Ragone, Santiago Catalino Arredes y Margarita Martínez de Leal", de fecha 12/12/2011.

4 Tribunal Oral en lo Criminal Federal de Tucumán, Expte. T-99/12: "Toledo de Ygel, María Elena s/ Denuncia”, de fecha 19-12-2013.

5 CNT 9616/2008/1/RH1; "Ingegnieros, María Gimena c/Techint Sociedad Anónima Compañía Técnica Internacional s/ accidete-les especial”, dictamen del Procurador Fiscal Victor Abramovich, de fecha 03-03/2017.

6 En línea en: Centro de Información Judicial. En línea en: http://www.cij.gov.ar/nota-25380-LaCorte-Suprema-por-mayor-a-ratific-su-precedente-sobre-la-prescripci-n-de-acciones-civiles-contra-el-Estado-enjuicios-de-lesa-humanidad.html 
El magistrado Maqueda en su voto disidente reconoció el derecho de las víctimas de delitos de lesa humanidad a obtener del Estado la reparación de los daños causados sin sujeción a plazo alguno de prescripción (Centro de Información Judicial).

Maqueda dijo que esta declaración de imprescriptibilidad de las acciones resarcitorias tuvo fundamento en las normas y principios del sistema internacional de protección de los derechos humanos, que recepta la propia $\mathrm{CN}$, y que fueran ya aplicados en la jurisprudencia desarrollada por la C.S.J.N. al declarar la imposibilidad de amnistiar, indultar o declarar la prescripción penal en materia delitos de lesa humanidad (Centro de Información Judicial).

También resaltó que estos postulados fueron recogidos por el legislador en el nuevo $\mathrm{CCyCN}$ al adecuar a ellos la legislación infraconstitucional (Centro de Información Judicial).

Maqueda, en su voto, sostuvo que del derecho internacional consuetudinario, receptado por la Constitución Nacional al momento de su sanción, y de las normas del derecho convencional a las que la reforma constitucional de 1994 les dio esa misma jerarquía, se deriva que el Estado argentino ha asumido un fuerte compromiso internacional en virtud del cual la garantía de la tutela judicial efectiva de los derechos humanos comprende tanto el derecho de las víctimas y sus familiares al conocimiento de la verdad y el castigo penal de los autores de delitos de lesa humanidad como el de obtener una reparación de los daños sufridos (Centro de Información Judicial).

El juez Maqueda, advirtió que tanto la acción de daños y perjuicios como la penal derivan de un mismo crimen internacional. Por lo tanto, reconocida la imprescriptibilidad de los delitos de lesa humanidad desde la óptica penal, por constituir éstos serios actos inhumanos que por su extensión y gravedad van más allá de los límites de lo tolerable para la comunidad internacional, sería inadmisible sostener que la reparación económica a cargo del Estado de las consecuencias de esos crímenes pueda quedar sujeta a algún plazo de prescripción (Centro de Información Judicial).

Maqueda destaca que la fuente de la responsabilidad en materia de delitos de lesa humanidad se encuentra en las normas y principios del Derecho Internacional de los Derechos Humanos, que persiguen la protección de un bien jurídico que se halla en un plano superior: la dignidad humana (Centro de Información Judicial).

El juez Maqueda concluye en que la acción indemnizatoria que puede derivarse de esos delitos tiene carácter humanitario y que, en consecuencia,por sobre los objetivos que persigue el instituto de la prescripción debe primar la obligación asumida por el Estado Argentino de garantizar la reparación a las víctimas, de forma tal que se asegure su realización como seres humanos y se restaure su dignidad (Centro de Información Judicial).

El juez Rosatti, en su voto en disidencia, sostuvo que si es imprescriptible la persecución de los delitos de lesa humanidad-consecuencia penal-, como ya lo ha sostenido la Corte en diversos precedentes, debe ser imprescriptible también el derecho de las víctimas para reclamar la reparación pecuniaria -consecuencia indemnizatoria-, cuando los daños estén debidamente acreditados (Centro de Información Judicial). 
Fundamentó esta conclusión en que resulta irrazonable y absurdo que el mismo Estado (si bien no el mismo Gobierno), causante de un perjuicio de la magnitud propia de los delitos de lesa humanidad, se escude en el instituto de la prescripción liberatoria para no cumplir con una obligación única, indiscutible y de naturaleza esencialmente reparatoria, que aunque pueda ser intelectualmente separable de su aspecto penal, es moralmente indisoluble.

El juez Rosatti sustentó su voto disidente en el "principio general" que establece el artículo 19 de la $\mathrm{CN}$, según el cual se "prohíbe a los 'hombres' perjudicar los derechos de un tercero", principio que -como ha dicho la Corte reiteradas veces- se encuentra "entrañablemente vinculado a la idea de reparación"; y en diversas disposiciones internacionales, tales como el Conjunto de Principios Actualizados para la Protección y Promoción de los Derechos Humanos mediante la Lucha contra la Impunidad (Comisión de Derechos Humanos, Naciones Unidas, E/CN.4/2005/102/Add.1), en el que se destaca la necesidad de adoptar medidas nacionales e internacionales para que, en interés de las víctimas de violaciones de los derechos humanos, se asegure conjuntamente el respeto efectivo del derecho a saber que entraña el derecho a la verdad, el derecho a la justicia y el derecho a obtener una reparación, sin los cuales no puede haber recurso eficaz contra las consecuencias nefastas de la impunidad (Centro de Información Judicial).

Finalmente, el juez Rosatti invocó los Principios y Directrices Básicos sobre el Derecho de las Víctimas de Violaciones Manifiestas de las Normas Internacionales de Derechos Humanos y de Violaciones Graves del Derecho Internacional Humanitario a Interponer Recursos y Obtener Reparaciones, aprobados por la Asamblea General de las Naciones Unidas en la resolución 60/147, por el que se reconoce que, al hacer valer el derecho de las víctimas a interponer recursos y obtener reparaciones, la comunidad internacional hace honor a su palabra respecto del sufrimiento de las mismas, los supervivientes y las generaciones futuras, y reafirma los principios jurídicos internacionales de responsabilidad, justicia y estado de derecho (Centro de Información Judicial).

\section{b.- Doctrina: Al respecto, Morlachetti dice que}

(...) es a partir de su obligación básica de respetar y de asegurar que se respeten y aplicar las normas internacionales de derechos humanos que el Estado debe garantizar el acceso igual y efectivo a la justicia; a la reparación adecuada, efectiva y rápida del daño sufrido; y el acceso a información pertinente sobre los abusos y los mecanismos de reparación. $\mathrm{Y}$ es en esta inteligencia de que la reparación integral impuesta por la Convención Americana sobre Derechos Humanos (LA 1994-B-1615) y la normativa internacional debe ser asumida por el Estado como un deber jurídico propio a fin de no incurrir en responsabilidad internacional, que la acción civil o administrativa que persiga la reparación de las víctimas en casos de crímenes de lesa humanidad no debería estar sujeta a prescripción (Morlachetti, 2013). 
Botassi (2013) dice que así

(...) como quedó superado el debate respecto de la vindicta penal el tema todavía registra algún grado de controversia con relación a la posibilidad de prescripción de la acción (mal llamada "civil") indemnizatoria. En este terreno las aguas están divididas, registrándose posturas partidarias de la extinción de la acción a los dos años de ocurridos los hechos por aplicación del artículo 4037 del Código Civil (salvo naturalmente circunstancias excepcionales de suspensión o interrupción) sin que falten quienes piensan que la imprescriptibilidad de la pena se extiende a la acción indemnizatoria. Nos enrolamos decididamente en la segunda postura, no sólo porque desde el punto de vista axiológico es la que mejor atiende a la posición de la victima sino también por estrictas razones jurídicas(...)

Continua Botassi (2013) afirmando con total claridad que

(...) Consideramos que tanto la responsabilidad penal como la reparatoria resultan inescindibles debido a que la obligación de los Estados no se agota con el juzgamiento y condena de los culpables del ilícito sino que se extiende al deber de resarcir a las víctimas. Sobre todo si se advierte que la Convención de Viena sobre el Derecho de los Tratados dispone en su artículo 27 que los Estados partes no pueden invocar reglas de derecho interno para desconocer sus compromisos internacionales. Diferenciar los aspectos penales y los civiles de los delitos de lesa humanidad, para concluir que la reparación de los daños queda burlada debido al transcurso del tiempo, hace incumplir la obligación internacional de compensar a las víctimas del terrorismo de Estado antes recordada, habilitando la jurisprudencia de la Corte Interamericana de Derechos Humanos"

Para concluir su análisis, Botassi (2013) nos dice que

(...) parece evidente que desde la óptica de los objetivos y funciones del Estado la prescripción extintiva de los derechos individuales debe admitirse excepcionalmente cuando resulte equitativa por dirimir conflictos dudosos según las circunstancias de la causa. En materia de delitos de lesa humanidad, en cambio, probada la autoría y responsabilidad de agentes estatales en sentido amplio (incluyendo que participaron de los hechos dañosos), retornando con las penurias conocidas el Estado de Derecho no resulta éticamente tolerable, ni jurídicamente procedente, privar de compensación a quienes soportaron gravísimos daños morales, psíquicos, espirituales y también patrimoniales. 
En una obra imprescindible para esta cuestión, Carlos Alberto Díaz (2006) sostuvo con acierto que

(...) el principio resarcitorio es el elemento per se de la imprescriptibilidad. No es el penal, porque éste es finito, se agota con la desaparición de los responsables fácticos e ideológicos de la barbarie. En cambio los Estados responsables persisten en el tiempo más allá de la vida de los genocidas. En consecuencia, la cualidad que hace a la existencia de la imprescriptibilidad es la resarcitoria porque al presuponerse la perpetuidad de los Estados modernos ésta se extiende ilimitadamente en el tiempo... porque es el Estado en definitiva quien por acción $\mathrm{u}$ omisión ha provocado el daño resarcible (137).

Por otra parte, Eduardo Jiménez (2010) sostuvo con razón

(...) que la prescripción no puede separarse sin más de la pretensión jurídicamente demandable (CSJN, Fallos: 308:1101). En consecuencia, cuando nos encontramos ante un reclamo indemnizatorio generado por un accionar ilícito cuya acción penal debe considerarse imprescriptible por derivar de la comisión de un delito de lesa humanidad, y dado que en estas cuestiones, la acción civil es una consecuencia del hecho ilícito mencionado, con cierta dosis de accesoriedad que sella su suerte, sobre todo teniendo en cuenta el régimen del derecho internacional en vigor respecto de ésta cuestión, esta última acción debe considerarse también imprescriptible.

Jiménez concluye diciendo "Entiendo que los términos de la norma son suficientemente precisos como para afirmar que las acciones (también las civiles a fin de obtener las reparaciones pertinentes) son imprescriptibles (Cfr. Gelli, María Angélica)"

Jorge Rubén Afarian al respecto nos dice que "De esta manera, finaliza una discusión como la vigente en "Olivares", en la que la Corte Suprema entendió que: "Ninguna de las normas del Pacto de San José de Costa Rica establece la imprescriptibilidad de las acciones civiles de indemnización de perjuicios ocasionados por la privación de la libertad que tenga lugar en desmedro de los principios aceptados por el pacto.” (CSJN, 1988).

No se trata "de la primera norma positiva que lo establece explícitamente para ciertos delitos: el art. 36 de la Constitución Nacional, producto de la reforma de 1994, impone las sanciones del art. 29 a quienes, como consecuencia de "actos de fuerza contra el orden institucional y el sistema democrático" -actos insanablemente nulos-, "usurparen funciones previstas para las autoridades de esta Constitución o de las provincias, los que responderán civil y penalmente por sus actos. Las acciones respectivas serán imprescriptibles" (Jiménez, cita Online: AR/DOC/5585/2010).

Como puede apreciarse 
(...) contamos con una norma de similares características incluso en la Carta Magna de la Nación, y desde hace más de dos décadas. El artículo del nuevo Código Civil y Comercial sólo viene a completar la exigencia constitucional de una reparación integral ante vejaciones y violaciones de derechos fundamentales, más aún luego de la reforma constitucional de 1994, con la inclusión de los nuevos derechos y garantías, además los tratados y declaraciones de derechos humanos con jerarquía constitucional (artículo 75, inciso 22)” (Jiménez, cita Online: AR/DOC/5585/2010)

Continúa diciendo Afarian que "Tan solo por citar un ejemplo, la Convención Americana sobre Derechos Humanos (Pacto de San José de Costa Rica), en su artículo 63 , inciso $1^{\circ}$, establece el derecho a una justa indemnización a la parte lesionada" (Jiménez, cita Online: AR/DOC/5585/2010).

Afarian con claridad dice que "La idea del instituto de la prescripción es sustentada por, entre otros valores, la seguridad jurídica y la estabilidad de los negocios. Empero, cuando de violaciones de Derechos Humanos se trata, estas dos consideraciones son peligrosas " (Jiménez, cita Online: AR/DOC/5585/2010).

Dice Afarian que "Concuerdo con Juan Justo cuando dice: "La idea de que la seguridad jurídica puede preservarse mediante la conservación de actos de lesa humanidad parece desatender que nuestra forma de convivencia se asienta en que la certeza de las relaciones y la seguridad jurídica se garantizan mediante el respeto de los derechos humanos, con lo cual disociarlos no parece conteste con una firme convicción en pos del Estado de Derecho " (Jiménez, cita Online: AR/DOC/5585/2010).

Finalmente, Afarian afirma que "No puede predicarse la seguridad jurídica cuando ésta sustenta resultados injustos y contrarios a los mayores de derechos de las personas. La prescripción civil es utilizada cuando la relación se sustenta en la igualdad contractual de las partes (como la celebración de un contrato de compraventa o la locación de un inmueble), y no, como en estos casos, cuando estamos frente a casos de terrorismo de Estado " (Jiménez, cita Online: AR/DOC/5585/2010).

$\mathrm{Al}$ respecto, en la doctrina chilena encontramos la posición de Mario Campos Poblete, Gonzalo Aguilar Cavallo y Carlos Céspedes Muñoz.

El primero de los mencionados, nos dice con toda razón al referirse al Código Civil chileno, cuando expresa que "Ello es aplicable a las relaciones entre particulares, o de estos con el Estado en el plano doméstico, pues el CC no fue elaborado para regir la responsabilidad internacional del Estado que se origina con los crímenes de lesa humanidad " (Campos:155)

Asimismo, vale tener presente la posición brillante del jurista Aguilar Cavallo, quien fundamenta su argumentación en seis pilares concretos para afirmar la imprescriptibilidad de las acciones civiles por daños derivadas de crímenes de lesa humanidad, a saber: 
Primero: Principio de Derecho Internacional Convencional ${ }^{7}$ : El art. 29 del Estatuto de la CPI señala que "los crímenes de la competencia de la Corte no prescribirán”, observa el autor que no se distingue entre la acción civil o penal, siendo ambas imprescriptibles (Campos :155).

Segundo: El falso argumento de la seguridad jurídica: Aguilar Cavallo (2008:178) se pregunta si la seguridad y certeza jurídica, fundamentos de la prescripción, son para las víctimas y sus familiares o para los victimarios. Ello lleva a revisar si la prescripción es una institución absoluta en el ámbito de los ordenamientos jurídicos, a lo cual debemos esgrimir que "la prescripción no es una institución universal. Existen sistemas jurídicos, como por ejemplo los anglosajones, que no la conocen o al menos no le dan un carácter general"47. En esta línea, debemos entender que los crímenes contra la humanidad se enmarcan en el DIDH, que tiene por eje central la dignidad de la persona humana, donde el bien jurídico protegido está en un plano superior (Aguilar Cavallo, 2008:156).

Tercero: Principio de coherencia(Aguilar Cavallo, 2008:182) : Si de un mismo hecho nacen ciertas acciones, darles un tratamiento distinto no guarda coherencia, por lo tanto, si de los crímenes contra la humanidad derivan acciones, civil y penal, ambas deben tener la misma suerte, es decir, se excepcionan de la prescripción extintiva. Este fundamento es rebatido por quienes señalan que desde la época de la codificación ambas acciones han sido reguladas de forma distinta, y están establecidas con objetivos diferentes. La acción penal lleva a cabo el juicio de reproche desde la perspectiva de la culpabilidad, busca la paz social y, por otro lado, la acción civil es la proyectada a establecer la responsabilidad del infractor y recibir la reparación del daño, que será para la satisfacción del ofendido. Sin embargo, desde la óptica de los crímenes internacionales se les debe dar un trato igualitario, debido a que los bienes jurídicos protegidos van más allá de la paz de una sociedad y de la propiedad de un ciudadano, se ampara la dignidad de la humanidad completa (Aguilar Cavallo, 2008:182).

Cuarto: Enfoque centrado en las víctimas y en la humanidad (Aguilar Cavallo, 2008:183): Aguilar Cavallo expresa que el derecho penal interno está centrado en el reo, pero el DPI está elaborado en torno a la víctima, por lo cual, frente a los crímenes internacionales, los jueces nacionales deben realizar un análisis y aplicación de las normas de una forma diferente. Esta concepción obedece a "un cambio de la cuestión moral dentro del derecho, el cual fue iniciado por la imprescriptibilidad de los crímenes contra la humanidad, que es la primera piedra de un derecho universal" (Poblete Campos, 2008:157).

Quinto: Principio finalista (Aguilar Cavallo, 2008:182) : La persecución de los crímenes de lesa humanidad tiene un fin preventivo, uno sancionador y uno reparador, frente a los cuales, si opera la prescripción civil, no permitirá que se cumplan a cabalidad los citados fines. Estos obedecen a "la relación del derecho internacional junto a la moral, que parece haber llevado a una legalización necesaria de la misma -tal es la imprescriptibilidad de los crímenes contra la

7 Aguilar Cavallo, Gonzalo, Crímenes internacionales y la imprescriptibilidad de la acción penal y civil: referencia al caso chileno”, en Revista Ius et Praxis, año 14 n². Talca, Chile: Universidad de Talca, 2008, pp. 178 . 
humanidad- una justificación moral del poder, en nombre de un buen derecho" (Poblete Campos, 2008:159).

Sexto: Principio de la reparación integral(Aguilar Cavallo, 2008:183): Este principio es un tema de vital importancia, se traduce en un derecho para el afectado y una obligación para el infractor de los DD.HH., y se posiciona como el medio palpable de la represión de los crímenes contra la humanidad. La reparación integral presenta múltiples funciones, a saber; disuadir, sancionar, ejemplificar, y, sobre todo, restablecer el orden quebrantado cuando sea posible, o de una forma sustitutiva. Zaffaroni nos enseña que "invocar la simple prescripción civil para negar cualquier derecho de reparación o de restitución en caso de crímenes contra la humanidad cometidos siglos anteriores no es una mera cuestión de neutralización del reclamo, sino un verdadero escándalo jurídico" (Poblete Campos, 2008:183).

A su turno, Céspedes Muñoz (2011) nos dice

Finalmente y para el evento de existir alguna duda sobre si aplicar el régimen del Derecho Internacional Humanitario o del Código Civil, debe estarse al estatuto más beneficioso para la víctima, aplicando el principio pro homine, que en materia de responsabilidad extracontractual se denomina pro damnato o favor victimae. El principio pro damnato es un principio tendencial del Derecho de Daños que persigue asegurar la correspondiente indemnización a las víctimas, más que moralizar la conducta de los autores de los daños. Este principio se materializa en la siguiente máxima: “... por regla general, todos los perjuicios y riesgos que la vida social ocasiona, deben dar lugar a resarcimiento, salvo que una razón excepcional obligue a dejar al dañado solo frente al daño...(147)

Este principio, dice Céspedes Muñoz, "no es más que la aplicación de otro de mayor entidad, que erige a la defensa del más débil en la principal preocupación del Derecho moderno, como lo denominaba JOSSERAND en su trabajo "La protección de los débiles por el derecho” (Céspedes Muñoz 2011: 148).

Por lo tanto, concluye Céspedes Muñoz, "atendida la naturaleza de los crímenes de lesa humanidad, no se aprecian razones para dejar a los ofendidos solos con su sufrimiento: se impone, en consecuencia, el deber de indemnizar. Es decir, se protege a la parte más débil: la víctima de tales delitos " (Céspedes Muñoz 2011: 148).

\section{III.- Conclusión}

Como corolario, luego de analizadas las dos posturas doctrinarias y jurisprudenciales existentes sobre la imprescriptibilidad de las acciones civiles resarcitorias por los daños derivados de los delitos de lesa humanidad, y también haber examinado las normativas respectivas, entiendo que todos los argumentos a favor de la prescripción de dicha acción han sido claramente rebatidos y puestos en crisis, tal como lo demuestra el último fallo de la CSJN en donde 3 de los 5 
integrantes votaron a favor de la postura negatoria y los otros 2 por la contraria, lo que devela que la cuestión lejos de cerrarse se encuentra en pleno debate.

Además, con la incorporación del art. 2.561 in fine al nuevo $\mathrm{CCyCN}$, que establece la imprescriptibilidad de las acciones resarcitorias derivadas de los crímenes contra la humanidad, en concordancia con el art. 7 del mismo código, queda definitivamente esclarecido que el Estado argentino decidió no apartarse del ordenamiento jurídico.

Por lo tanto, la posición adoptada es la que, como antes ya se ha afirmado, entiendo que permite compatibilizar con mayor ductilidad las prescripciones del derecho interno argentino con las normas internacionales que el Estado argentino debe observar en lo relativo al deber de reparar adecuadamente un daño frente a la vulneración de una obligación internacional.

A pesar de ello, resulta pertinente formular una especificación adicional, o sea, considero que reconocer la imprescriptibilidad de la acción civil resarcitoria resultante de los daños producidos como consecuencia de la comisión de delitos de lesa humanidad constituye una ajustada aplicación a la cuestión en estudio del Principio Pro Homine.

Esto es, de aquel criterio hermenéutico que comprende a todo el derecho de los Derecho Humanos que manda acudir a la norma más amplia, o a la interpretación más extensiva, cuando se trata de reconocer derechos protegidos e, inversamente, a la norma o a la interpretación más restringida cuando se trata de establecer restricciones permanentes al ejercicio de los derechos o su suspensión extraordinaria (Pinto Mónica, 2004: 163)

Más concisamente, entiendo que la posición descripta constituye una manifestación del imperativo jurídico internacional de proporcionar una tutela más refinada de las personas.

En suma, y como dijo el Juez Maqueda en la causa "Villamil", el deber estatal de indemnizar los daños causados por los delitos de lesa humanidad cometidos por el Terrorismo de Estado en las décadas del 70 y 80 en nuestro país no están sujetas a plazo de prescripción alguno. 


\section{IV.- Bibliografía}

ABRAMOVICH Víctor (2017). CNT 9616/2008/1/RH1; "Ingenieros, María Gimena c/Techint Sociedad Anónima Compañía Técnica Internacional s/ accidete-les especial", dictamen del Procurador Fiscal de fecha 03-03/2017.

AfARIAN, J. R. (2016). "Imprescriptibilidad de las acciones resarcitorias conexas a crímenes de lesa humanidad", en Derecho Global. Estudios sobre Derecho y Justicia, Buenos Aires, Año 1, Número 3, Abril - Julio 2016, ISSN 2448-5128.

Aguilar Cavallo, G. (2008). Crimenes internacionales y la imprescriptibilidad de la acción penal y civil: referencia al caso chileno", en Revista Ius et Praxis, año $14 \mathrm{n}^{\circ} 2$. Talca, Chile: Universidad de Talca.

BotAssi, C. A. (2013). "Lesa humanidad, responsabilidad civil del Estado y prescripción”, en La Ley 2013-C, 643, Cita Online: AR/DOC/1397/2013.

CÉSPEDES MUÑOZ, C. (2011). "Imprescriptibilidad de la acción civil derivada de la comisión de crímenes de lesa humanidad". Sentencia Excma. Corte Suprema de 08 de abril de 2010, en Revista de Derecho y Ciencias Penales No 16 (131-150), 2011, Universidad San Sebastián (Chile), ISSN 0718-302X, pp. 146-147.

DíAZ, C. A. (2006). La imprescriptibilidad Penal y Resarcitoria de los Crimines de Lesa Humanidad, Librería de la Paz, 2006, con Prólogo de Adolfo Pérez Esquivel.

GUIBOURG, R. (S/A). Imprescriptibilidad de la responsabilidad civil por crimenes contra la humanidad, La Ley -LL 2012-B-161.

JiMÉNEZ, E.P. (2010). "Acerca de la imprescriptibilidad de las acciones civiles para reclamar daños y perjuicios derivados de delitos de lesa humanidad", en La Ley RCyS2010-IX,84, Cita Online: AR/DOC/5585/2010.

Kemelmajer De CARluCCI, A. (2013). "Las medidas de reparación en las sentencias en las que la Argentina resultó condenada por la Corte Interamericana de Derechos Humanos, Sumario XII. La cuestión de la prescripción de la acción para reclamar la indemnización de los daños causados por ataques a los derechos humanos", en La Ley Online, Thomson Reuters, Cita Online AP/DOC/135/2013.

López HerRerA, E. S. (S/A). "La Corte Suprema de la Nación rechaza la imprescriptibilidad de la acción de daños sufridos por los familiares de desaparecidos durante la dictadura", en La Ley, Thomson Reuters, Cita Online: 0003/013600.

MARINO, M. D. (2017). "Imprescriptibilidad de la acción resarcitoria derivada de los crímenes de lesa humanidad y genocidio" en Línea en http://ccycn.congreso.gob.ar/export/hcdn/comisiones/especiales/cbunificacionc odigos/ponencias/lamatanza/pdf/LM 009 MARIA DANIELA MARINO VI.p df.

Montilla ZaVAlíA, F.A. (2016) "La acción de responsabilidad derivada del delito de lesa humanidad a la luz del Código Civil y Comercial y el régimen de responsabilidad del Estado", en El Derecho, Buenos Aires, 27/04/2016, ISSN 1666 8987, N¹3.944, Año LIV, ED 267. 
Morlachetti, A. (S/A). "Crímenes de lesa humanidad. El deber internacional de la reparación integral y la imprescriptibilidad de la acción civil”, en La Ley, Thomson Reuters, Cita Online: 0003/013312.

POBlete CAMPOS, M. (2011). "La prescripción de las acciones reparatorias civiles emanadas de los crímenes de lesa humanidad", en Derechos y Humanidades, Talca Chile, ISSN 0716-9825, Nº 18.

CORTE Suprema de Justicia de la NACiÓn (1988). "Olivares, Jorge A. c. Gobierno Nacional", 16/08/1988.

CÁmara Federal de la Plata (2006). Sala II, "Villamil, Amelia Ana c/ Estado Nacional s/ Daños y perjuicios", 23/11/2006, JA 2007-III-647.

JuzGado Federal No 2 De Mar del Plata, Expte. 77331/8: "Bozzi, Carlos c/Estado Nacional s/ Daños y Perjuicios Ordinario", de fecha 2010.

"Oesterheld, Diana Irene s/ su secuestro y desaparición. Inicidente de apelación”, Expte. 50.656/08, sentencia del 19-06-2008.

Tribunal Oral en lo Criminal Federal de Salta, Expte. No 3115/09: "c/HERRERA, Rubén Nelson; HERRERA, Pedro Javier; GENTIL, Miguel Raúl; MULHALL, Carlos Alberto; ZANETTO, Jorge Héctor; GUIL, Joaquín y SORAIRE, Andrés del Valle s/Encubrimiento en concurso ideal con el tipo penal de omisión de represión de delincuentes; homicidio calificado en dos hechos en concurso real y lesiones; coacción agravada y lesiones, en perjuicio de Miguel Ragone, Santiago Catalino Arredes y Margarita Martínez de Leal", de fecha $12 / 12 / 2011$.

Tribunal Oral en lo Criminal Federal de Tucumán, Expte. T-99/12: "Toledo de Ygel, María Elena s/ Denuncia”, de fecha 19-12-2013.

Tribunal Oral en lo Criminal Federal de CatamarCa, TOCF, Expte. Nם 16/12 "Mirtha Clerici y otros s/ solicita medidas procesales ( $\left.{ }^{\circ} 4148 / 04\right)$ ", Sentencia de fecha 08/10/2013. 